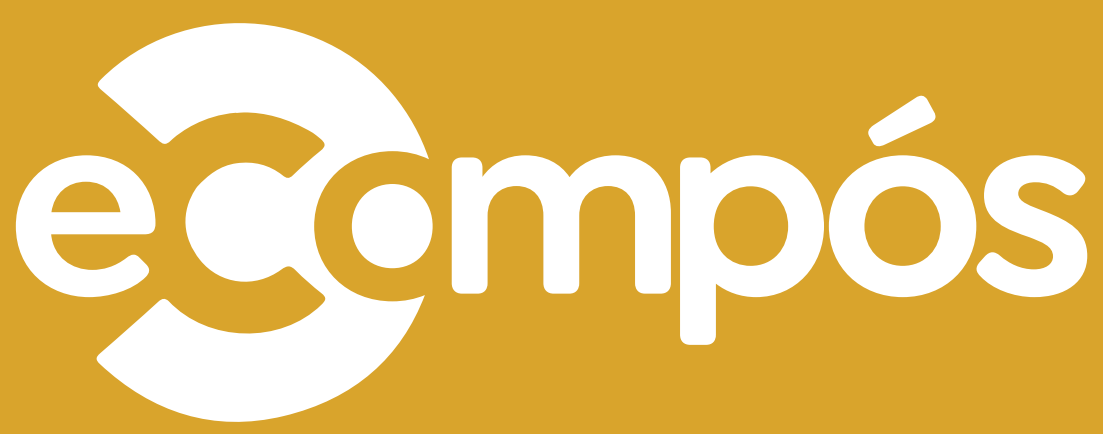

Revista da Associação Nacional dos Programas de Pós-Graduação em Comunicação

ISSN 1808-2599, v. 24, jan-dez,

publicação contínua, 2021, p. 1-23.

doi.org/10.30962/ec.2189

Construindo espaços fluidos

A potência narrativa da incerteza nas análises de jornalismo

\section{CLARA CÂMARA}

Universidade Federal Fluminense, Niterói, Rio de Janeiro, Brasil

\section{ANDRÉ BONSANTO}

Universidade do Estado do Rio Grande do Norte, Mossoró, Rio Grande do Norte, Brasil

\section{ID 2189}

Recebido em 08/06/2020

Aceito em 16/11/2020 


\section{/ resumo}

Neste artigo, refletimos sobre o jornalismo e a necessidade de reformulação das relações deste com suas próprias narrativas de certeza. Traçamos um caminho pelos estudos de jornalismo e os de narrativa, trazendo o exemplo sobre as manchas de óleo que apareceram nas praias do litoral do Nordeste brasileiro, em 2019. Essas narrativas de incerteza e imprecisão constroem espaços fluidos nos quais pensamos o lugar de privilégio que o jornalismo - mediador e narrador do mundo - construiu para si, e o quanto os que se dedicam a analisar suas narrativas também precisam repensar esses caminhos de idealizações.

Palavras-chave: Jornalismo. Narrativa. (In)certeza.

\section{Construyendo espacios fluidos: el poder narrativo de la incertidumbre en el análisis periodístico}

En este artículo, reflexionamos sobre el periodismo y la necesidad de reformular sus relaciones con sus propias narrativas. Trazamos un camino a través del periodismo y los estudios narrativos, trayendo el ejemplo de las manchas de aceite que aparecieron en las playas de la costa noreste de Brasil en 2019. Estas narrativas de incertidumbre e imprecisión construyen espacios fluidos en los que pensamos que el lugar de privilegio que $\mathrm{El}$ periodismo, mediador y narrador del mundo, se ha construido por sí mismo, y la medida en que aquellos que se dedican a analizar sus narrativas también necesitan repensar estos caminos de idealización.

Palabras clave: Periodismo. Narrativa.

(In)certidumbre.

\section{Building fluid spaces: the narrative power of uncertainty in journalism analysis}

In this article, we reflect on journalism and the need to reformulate its relations with its own certain narratives. We traced a path through journalism and narrative studies, bringing the example of the oil stains that appeared on the beaches of the Brazilian northeastern coast, in 2019. These narratives of uncertainty and imprecision build fluid spaces in which we think the place of privilege that journalism - mediator and narrator of the world - has built for itself, and the extent to which those who dedicate themselves to analyzing their narratives also need to rethink these paths of idealization.

Keywords: Journalism. Narrative. (Un)certainty. 


\section{/ autores}

\section{eccompós}

\section{Clara CÂMARA}

Doutora em Comunicação pelo Programa de Pós-Graduação em Comunicação da Universidade Federal Fluminense.

Universidade Federal Fluminense, Niterói, Rio de Janeiro, Brasil

E-mail: clarabcamara@gmail.com

\section{ORCID}

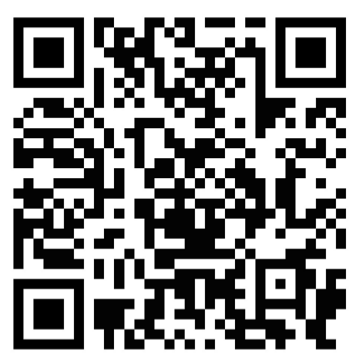

\section{André BONSANTO}

Universidade do Estado do Rio Grande do Norte, Mossoró, Rio Grande do Norte, Brasil Doutor em Comunicação pelo Programa de Pós-Graduação em Comunicação da Universidade Federal Fluminense. Bolsista de Pós-Doutorado (PNPD/Capes) e professor colaborador no Programa de Pósgraduação em Ciências Sociais e Humanas da Universidade do Estado do Rio Grande do Norte - UERN.

Universidade do Estado do Rio Grande do Norte, Mossoró, Rio Grande do Norte, Brasil.

E-mail: andrebonsanto@gmail.com

\section{ORCID}

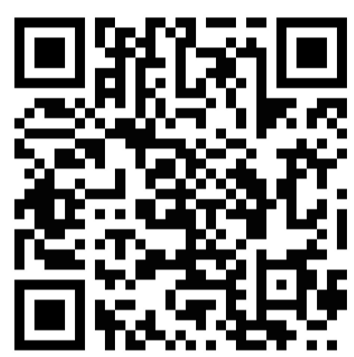




\section{Introdução}

Imprecisão, nebulosidade, instabilidade. O jornalismo está acostumado a lidar com tudo que nega para si e ainda garantir seu lugar de autoridade. As questões da pós-verdade escancaram um ponto antigo dos estudos de jornalismo: a construção de seu lugar de fala legítimo. Historicamente, o jornalismo, enquanto instituição, tem procurado (a)firmar suas "verdades" no entrelugar de uma realidade factual e objetivamente observável. Sem espaço para questionamentos mais evidentes, a lógica de seus discursos de autolegitimação passa a se constituir paradoxalmente por uma historicidade quase que a-histórica, privilegiando muito mais as permanências do que suas brechas e possiveis rupturas.

Neste artigo, propomos uma reflexão a respeito dessa questão. Para isso, trazemos um exemplo como ilustração: indícios a partir de narrativas jornalísticas sobre as manchas de óleo que apareceram nas praias do litoral do Nordeste brasileiro, em 2019. À época, pouco se sabia a respeito da origem do óleo, a dimensão de seu estrago, como enfrentá-lo, ou mesmo se havia outras invasões do mesmo tipo prestes a ocorrer.

Encaramos os fragmentos jornalísticos sobre esse episódio como constitutivos da paisagem fluída de um Brasil composto de rastros, restos e ruínas que se abrem a novos horizontes. São narrativas opostas, fragmentadas, essencialmente como todo ato de narrar, ainda que o jornalismo, nas tentativas de seu (auto) legitimar, acabe por negligenciar suas aparentes contradições e inconsistências. Aqui, então, travamos o exercício de expô-las, na pretensão que se ampliem e complexifiquem as perspectivas de estudos de jornalismo na fluidez de narrativas e acontecimentos incertos.

Para isso, na primeira parte do artigo, revisitamos algumas questões essenciais sobre jornalismo e narrativa. Apontamos nosso entendimento sobre as narrativas jornalísticas e reforçamos seu potencial construtor. Já na segunda parte, buscamos tensionar as barreiras que ainda pretendem estabelecer as narrativas jornalísticas como previamente imbuídas de estatutos de verdade - e, para isso, parecem se ancorar na abstração do "fato". Por fim, na terceira parte, apresentamos uma possibilidade de compreensão que dê conta de apreender realidades dispersas e fragmentadas.

A partir da fluidez narrativa das notícias a respeito das manchas de óleo nas praias nordestinas, questionamos: se não há concretude, não há discurso jornalístico legítimo? Usamos reflexões a respeito do espaço para argumentar justamente o oposto: que o jornalismo constrói seus discursos também a partir de narrações de espaços fluidos. Ainda, não é a imprecisão que deslegitima as narrativas jornalísticas, mas sua incansável tentativa de emular verdades - unas, factuais, sólidas, ou na sua nomenclatura clássica: objetivas.

\section{Jornalismo e narrativa: noções preliminares e complementares}

Este trabalho é constituído a partir de um olhar sobre o jornalismo que compreende as notícias como narrativas. Nesse sentido, e para fins de localização desse debate, é relevante destacar as ideias de Bird e Dardenne (1993), os quais afirmam que as notícias devem ser vistas como mitos. Essa compreensão se insere em uma perspectiva proposta também por Motta (1997) e problematizada por Albuquerque (2000) - e para a qual também convergimos, com algumas considerações.

Ainda segundo Bird e Dardenne (1993), enxergar as notícias como narrativas é focar no modo como as notícias são narradas, considerando como parâmetro o afastamento ou a proximidade do registro de dados. Isso significa que, ao se afastar, gradativamente, de um registro, que é meramente processual, a notícia estaria se aproximando de uma forma mais narrativa. Nesse sentido, quanto mais narrativa, ou seja, mais próxima da maneira de contar es/histórias que conhecemos, mais compreensivel aos leitores. 
De acordo com a proposta de Motta (1997) de aplicação dos estudos narrativos na análise jornalística, enxergar o jornalismo como narrativa é útil para entender a constituição dos chamados fait divers. Por outro lado, em outra argumentação, Albuquerque (2000) propõe a ampliação desse espectro de consideração e afirma que pensar o caráter narrativo é relevante tanto para as fait divers quanto às hard news, e que essa proposta visa pensar a cultura profissional jornalística. Isso porque, de acordo com o autor, as hard news são notícias que precisam muito mais de explicações do que as notícias enquadradas como fait divers. No entanto, a própria consideração da existência dessa dicotomia nos é problemática, embora recorrente.

Em todos esses exemplos ainda há o reconhecimento de uma dualidade. Isso, diante do que é argumentado, insiste em uma oposição que tende a não contemplar as particularidades da narrativa jornalística e as suas transformações, principalmente no que diz respeito à cobertura política (CÂMARA, 2019). A partir dessas inquietações, apoiamo-nos nas considerações feitas por esses autores, mas também tentando sinalizar uma nova leitura a respeito das análises das narrativas jornalísticas, alinhada com a dissolução dessas fronteiras. Por ora, utilizamos a ideia geral e abrangente de que as notícias servem para descortinar questões políticas e culturais de uma época (SCHUDSON, 1982).

Deixamos de lado, assim, o que parece ser um dos grandes terrenos de disputa das narrativas jornalísticas, que é o seu discurso que se pauta pela pretensão de verdade, afeito à apresentação de fatos verificados, em uma demonstração de sua herança com certos pressupostos positivistas (RESENDE, 2004). Essa questão não é nova, nem carece de debates. Pelo contrário, como todo campo de batalhas acadêmicas, o terreno que trata das narrativas tem sido extensamente explorado, demarcado e também amplamente contestado. Na teoria literária, essas disputas ocorrem há mais tempo, sendo Propp (2002), Todorov (1969) e Barthes et al. (1971) alguns de seus expoentes.

Para Todorov (1969), por exemplo, a narrativa é uma representação da temporalidade. Para ele, deve-se considerar a narrativa como representação capaz de organizar eventos distintos em um tempo específico. A relação entre a narrativa e o tempo se dá, então, através da capacidade de sistematização desses dois elementos, resultando em um desencadeamento lógico e cronológico de eventos. Em uma aproximação inicial com a proposta deste artigo, a perspectiva estruturalista desempenha um papel-chave: como organizadora dos elementos que devem ser levados em consideração na análise e como estruturadora de um caminho inicial para efetuar essa análise.

No entanto, passadas essas etapas, percebe-se a necessidade de transpor alguns engessamentos inerentes ao estruturalismo, principalmente no que se refere à compreensão de narrativa. Não por acaso as contribuições de Ricoeur (1995) nos são essenciais para a análise.

Em sua crítica à visão estruturalista da narrativa, o autor explica que há uma negligência desta ao não perceber que a dimensão interpretativa não pode transpor a dimensão episódica sem suprimir a própria estrutura. Ou seja, é improvável que a organização dos eventos em um dado tempo, nos moldes estruturais, seja o suficiente para se compreender o significado desses eventos, em separado e em conjunto. Os sentidos podem estar contidos nessa estrutura, mas são também exteriores à própria organização dos eventos e precisam ser levados em conta. E isso não pode ser feito sem que se altere a percepção da estrutura.

Em se tratando do jornalismo, essas disputas são mais recentes, mas não as eximem de controvérsias e longos debates, que são próprios das tentativas de demarcação (CÂMARA, 2019). Primordialmente, esses debates tentam compreender o que é narrativa, para que, diante dessa conceituação, se possa enquadrar o jornalismo como narrativa ou não. Um ponto de partida recorrente, como já mencionado, é enxergar a narrativa a partir de sua aproximação ou distanciamento de uma construção discursiva articulada em forma de estória. Quanto mais articulada com personagens, seguindo uma cronologia linear e alinhada com o ideal das fábulas, mais próximo se estaria da ideia de narrativa. Essa noção fica particularmente exposta quando Motta (2005) questiona se os enunciados objetivos do jornalismo podem constituir uma narrativa. A própria dúvida coloca em evidência a compreensão de narrativa vinculada a uma discursividade específica. 
Do mesmo modo, evidencia-se uma qualidade da narrativa, a narratividade, que pode ser compreendida como uma sequência de transformações inscritas no discurso (GREIMAS, 1976). A narratividade se coloca como uma característica da narrativa que a insere como intrinsecamente conectada com o tempo, já que as transformações que prevê, nos discursos, estão sempre vinculadas a uma temporalidade. Transformações acontecem ao longo do tempo, ou por causa da passagem do tempo.

Mas, considerando a produção jornalística, onde residiria a sua singularidade? Ou seja, o que faz do jornalismo uma narrativa? A dificuldade em se indicar a particularidade da narrativa jornalística é uma questão ainda em aberto.

Em sua releitura da tríplice mimese aristotélica, exposta para a compreensão da narrativa no papel de mediadora do tempo e da ação humana, Ricoeur (1995) expõe a articulação narrativa em três representações, as quais chama de mimese I, II e III. Em um esforço para simplificar sua densa explicação sobre as mimeses, sem causar ônus para a argumentação desenvolvida aqui, explica-se brevemente cada uma delas.

Sobre a primeira, mimese I, o autor sugere tratar de uma estrutura pré-narrativa que, ao mesmo tempo em que está implícita na estruturação narrativa, também a induz. A mimese I diz respeito ao mundo prefigurado, incluindo seus aspectos éticos, que existem previamente à narrativa. Ela, também, está presente nas mediações simbólicas, constituindo ações e, dessa forma, induzindo o desenvolvimento de narrativas. Já a mimese II e III correspondem, respectivamente, às estruturações narrativas em si e ao processo de reinterpretação e reapropriação contínuo a que a narrativa é submetida, na medida em que é posta em circulação. Enquanto a mimese II corresponde à mediação entre a mimese I e III, ao processo de configuração em que a presença de um narrador se torna marcante, a mimese III consiste na refiguração da narrativa. $\mathrm{Na}$ medida em que é percebida, a narrativa é reconfigurada a partir das próprias concepções de quem a interpreta. Nos termos do próprio Ricoeur (1995, p. 87), em resumo, "seguimos, pois, o destino de um tempo prefigurado em um tempo refigurado, pela mediação de um tempo configurado".

Nos estudos de jornalismo, essa noção tem sido incorporada às reflexões sobre a produção das narrativas jornalísticas, sua articulação nas páginas dos jornais e a sequente integração que são estimuladas com aqueles que as leem (CÂMARA, 2019). É possivel afirmar, então, que o jornalismo trilha caminhos de apreensão diversos, trabalhando com uma realidade que é configurada narrativamente.

\section{Fatos, acontecimento, discurso: apreensão e construções da realidade}

Ainda nesse contexto, poderíamos pensar que a realidade não seria exterior ao trabalho jornalístico, mas prefigurada por um processo de mediação que se constitui pela intriga. Pensar a configuração da intriga pela narrativa nos possibilita desenraizar a ideia de que o trabalho no jornalismo se daria exclusivamente por uma busca objetiva pela verdade dos fatos.

Desenraizar, no entanto, não significa negar sua existência, mas deslocar o problema a uma perspectiva que não nos soe tão transparente. É pela narrativa que poderemos destrinchar os meandros do discurso e perceber as possiveis estratégias que perpassam a produção noticiosa da prática jornalística. Como um lugar de mediação, a narrativa nos auxilia a pensar não apenas o contexto de produção em que se inscrevem suas es/histórias mas também e, principalmente, a dinamicidade de um espaço onde se articulam e se negociam sentidos (RESENDE, 2009).

A dinamicidade inerente às estratégias narrativas desnaturaliza, assim, o próprio discurso de uma verdade "do" jornalismo enquanto instituição. Um discurso que reitera constantemente os seus valores a partir de rituais normativos e evidencia brechas que se abrem em relação a práticas muitas vezes conflitantes entre si. Esses rituais, importantes para preservar a legitimidade/autoridade do campo, acabam por camuflar o processo de constituição de uma verdade que se inscreve concomitantemente "no" jornalismo (BONSANTO, 2018). 
Pensando dessa forma, Resende (2012) acredita que é possivel deslocarmos a questão da objetividade jornalística à luz de uma dimensão discursiva que problematize os modos de "re-presentar" (tornar de novo presente) os fatos e seus acontecimentos. De acordo com o autor, a re-presentação está relacionada às "distensões de conteúdo" que uma informação sofre ao ser colocada sob as mais diversas formas narrativas.

Se há distintos modos de representar um acontecimento no tempo - e no espaço, adicionamos - é porque, ainda segundo Resende (2012), a confecção narrativa pode ir além de meramente relatar os "fatos do presente", em sua pretensa objetividade, para pensar em um relato sobre o "presente dos fatos". A narrativa deslocaria, portanto, a "forma" da informação para sua multiplicidade de fala, onde a busca da verdade se torna uma apreensão dos possíveis que se abrem em discurso, ou seja, uma verdade que se pretende multifacetada e diversa.

Apesar de o autor estar problematizando um ideal sob o qual o jornalismo deveria se pautar, cabe a nós pensar que tal perspectiva insere o acontecimento em um regime de verdade que também leva em conta o seu poder de re(a)presentação. É pensar, portanto, no processo de dilatação e ressignificação do acontecimento no tempo e no espaço, um processo que se dá muitas vezes a partir de estratégias deliberadas de construção de sentido.

Entramos aqui nos "trópicos" onde todo discurso se constitui e refugia. Uma espécie de mudança de tom, ritmo e estilo que condiciona os sentidos de uma representação aparentemente "realista" do mundo. Falar em tropos discursivos, nesse sentido, é falar em desvios inevitáveis, fugidios, que se dão na apreensão da realidade cotidiana. Diante dos fatos, produzimos uma articulação narrativa que é essencialmente "mediadora" e pela qual, como bem atesta White (1994), não nos é possivel re(a)presentar as coisas como elas "realmente são". O que nos chega como discurso, enquanto atividade interpretativa, sempre se dá por uma falha de intenção, "deformada" por suas condições de possibilidade.

É a partir dessas condições de possibilidade que o acontecimento "se torna" (QUERÉ, 2005) aparentemente inteligivel, dilata-se por uma configuração narrativa circunscrita por rupturas e incertezas, entre o fato e o sentido. Mas ao procurar esclarecer contextos, revelar cenários de um mundo a comentar e explicar/compreender processos em curso, os acontecimentos se entrelaçam narrativamente por contingências que revelam, a todo momento, mudanças de situações, "peripécias" e alterações do acaso.

Inserido na história, o acontecimento jornalístico se legitimaria pela capacidade de "fazer falar" o que ele apresenta como fato, confrontando-o a partir de um caráter pluridimensional de busca da verdade, conforme pontua Ricoeur (1968). Desse modo, a realidade seria capturada pelo discurso jornalístico, que tornaria o acontecimento reconhecível em seu processo de mediação. Não há como compactuarmos, portanto, com a noção de que o jornalismo meramente reproduz aquilo que acontece na realidade, visto que sua construção implica um certo número de operações.

Ao presumir um "contrato" de comunicação, o jornalismo nomeia seus discursos, ordenando-os em um possivel mundo a comentar (CHARAUDEAU, 2006). Seguindo essa premissa, a realidade e aquilo que se materializa em texto não podem ser tratadas como categorias antagônicas, mas sim sobrepostas. 0 jornalismo, além de construir os acontecimentos, reproduz e se apropria dos mesmos, transformando-os a partir de sua dimensão de enunciação simbólica (FRANÇA, 2012).

Como parte de um contexto que the envolve e dota de sentido, mas que também abre novas possibilidades e ressignifica sua própria emergência, o acontecimento pode assim ser pensado sob uma perspectiva que transcenda seu caráter construtivista. Ele não é apenas aquilo que emerge em forma de discurso, pois está inscrito na experiência, gerando inquietações e rupturas. O jornalismo, dessa forma, faz falar, faz ver o acontecido, mas também faz-se ver. Sua articulação narrativa não é apenas texto, mas um texto inscrito em um círculo hermenêutico que demanda uma interpretação no e para o mundo (QUERÉ, 2005). 


\section{0 jornalismo para além de seu lugar de fala: narrativas de incerteza e a fissura dos fatos, (pós)verdade e flexibilizações}

Apesar de todas essas características que, a nosso ver, são fundamentais para problematizar a narrativa e o discurso jornalístico, acreditamos ser importante pontuar também que o jornalismo profissional, como instituição, historicamente procurou se atrelar a uma imagem que se diz portadora de relatos autorizados da modernidade, intentando se definir como um ator legítimo na busca pelo reconhecimento daquilo que acontece no mundo. A partir de meados do século XIX, quando uma concepção liberal de democracia e a mudança estrutural de uma "esfera pública" (HABERMAS, 2014) garantem à imprensa um espaço na sociedade para instituir junto ao público seu direito à "opinião", o jornalismo começa a se (a)firmar como uma importante arena de discussão pública no seu papel de mediador da moderna sociedade capitalista.

É nesse momento que começa a se legitimar discursivamente as narrativas de uma instituição que se dizia capaz de outorgar e articular "verdades" sobre uma realidade que se constituía cotidianamente. Um dos principais ingredientes para a emancipação de um campo específico destinado ao jornalismo é a emergência e consolidação de preceitos fundamentais da democracia, como a liberdade de expressão e de opinião. Jornalismo e democracia passam a partilhar de uma relação quase que simbiótica que dá ao campo legitimidade para exercer seu papel social.

Como um ismo dotado de sistemas de crença e prerrogativas próprias, o jornalismo - institucional e discursivamente falando - procurou se estabelecer a partir da configuração de certos termos de conveniência que, com o tempo, acabaram por se instituir como normas prescritas (NERONE, 2009, 2012). Essas normas, no entanto, não estariam ligadas a um valor epistemológico formal, mas a "atos de colonização" que atuariam com o intuito de diferenciar o "verdadeiro" jornalismo daquele feito por "bárbaros" ou amadores. A profissionalização do jornalismo, nesse caso, atuaria como uma importante estratégia para proteger as organizações de notícia e sua instituição (NERONE, 2013).

Ainda que não seja nossa preocupação perceber aqui como se deu esse processo de institucionalização, nos interessa pontuar que é a partir de um "sistema de representação de si" (BENNETI; HAGEN, 2010) que o jornalismo acaba por atrelar uma imagem própria do que seria sua prática, seus valores e premissas. Uma imagem que, é importante frisar, constrói uma representação da instituição e não necessariamente a realidade do fazer jornalístico. Como uma imagem, no entanto, ela é um poderoso instrumento para cristalizar identidades e, consequentemente, legitimar a autoridade do jornalismo.

Devemos nos preocupar, portanto, em pensar essas imagens como discursos que se configuram a partir de enunciados verticais, muitas vezes portadores de uma narrativa universal que atua como "estratégias de defesa" (LOPES, 2007) e/ou "rituais estratégicos" (TUCHMAN, 1993) para blindar a instituição e suas práticas. Dentro desse panorama, noções como as de "fato", "verdade" e "realidade", por exemplo, passam a assumir aquilo que Zelizer (2004) definiu como "god terms", conceitos incontestes que passam a legitimar uma prática a ser seguida e compartilhada.

A legitimidade da instituição jornalística está calcada, nesse sentido, em sua aparente função social, ou seja, no papel que ela cumpre dentro de determinada sociedade e que se fundamenta na tentativa de que tais valores sejam socialmente reconhecidos em sua função moral. Além disso, assumir esse caráter do jornalismo como portador do discurso do "real" pela notícia, daria margem, segundo Sodré (2009), à construção de um mito da neutralidade do jornalismo moderno, em que a instituição acabaria por encobrir os jogos de poder que presidem a constituição de seus próprios relatos.

Partindo de uma espécie de "realismo ingênuo", o jornalismo estabelece para si a estrutura paradigmática de um discurso verdadeiro, fundamentando sua deontologia basicamente sob o princípio da fidelidade aos fatos, ainda que o expondo às suas devidas críticas. Ao basear-se sob a premissa de que atuaria como uma espécie de "juízo oracular" que revela as coisas em sua essência, o jornalismo 
cria, assim, seus próprios papéis, uma imagem particular para reforçar e sacralizar seus ritos. Isso porque, em seu processo de autolegitimação, se torna fundamental "justificar sua função social como preciosa e insubstituível" e é por isso que o jornalismo gasta tanta energia "em afirmar a sua capacidade de nos dizer o que as coisas realmente são" (GOMES, 2009, p. 15).

É por isso que precisamos estar atentos ao alerta de Cornu (1999, p. 116): a aparente unanimidade desses discursos nos é, muitas vezes, enganadora. A verdade, por exemplo, "nunca é absoluta na sua expressão jornalística. [...] [ela tem] as marcas da ideologia, da política, da história". Os discursos de autolegitimação do jornalismo devem ser encarados, portanto, em sua historicidade, já que muitas dessas imagens emanam certo ar essencialista, procurando atuar como receituários daquilo que de fato o jornalismo "deveria ser" (JÁCOME, 2014, p. 56). Esses receituários negariam a multiplicidade constituinte do próprio jornalismo, vinculando-o a um tipo ideal, portador de um "modo de ser permanente", imutável, que se refletiria nos discursos de uma instituição baseada na isenção, na independência, no profissionalismo, no compromisso com a democracia, no interesse público etc.

Se quisermos problematizar o jornalismo para além de seus discursos de autolegitimação, precisamos desconfiar de princípios reguladores, totalizantes, a-históricos, que pretendem normatizar suas práticas e a imagem da instituição a partir de um determinado código padrão. Esses discursos se tornam sempre mais evidentes e explícitos em períodos de "crise", como nos parece bem perceptível no atual momento da chamada era da "pós-verdade" (BARBOSA, 2019; D'ANCONA, 2018; FILGUEIRAS, 2018). Nesses momentos parece que cabe ao jornalismo, e somente a ele, regular aquilo que deve ou não ser reconhecido como legítimo e verdadeiro, baseando-se sobretudo pela lógica da fidelidade aos fatos. É o que assegurou, por exemplo, Otavio Frias Filho, então diretor de redação da Folha de S. Paulo, em texto publicado meses antes de sua morte, em 2018. Para ele, o jornalismo profissional deveria continuar, mais do que nunca, adotando seus "rigorosos critérios" de produção das notícias, com o intuito de manter-se como "o farol a iluminar as fronteiras, sempre diluídas, entre o falso e o verdadeiro" (FRIAS FILHO, 2018, p. 44).

Ao assumir-se como um "farol" que direciona olhares sobre o que pode ou não ser considerado verdadeiro, o jornalismo profissional, representado aqui pela Folha, pretende se colocar, literalmente, acima da própria verdade, uma vez que ele teria capacidades próprias para ordenar a realidade da forma mais "rigorosa" possivel, a partir de sua produção noticiosa. É preciso que busquemos, portanto, superar as "bases ingênuas" (GOMES, 2009) que sustentam essas generalizações e acabam por reforçar dicotomias naturalizadas pela instituição. Dicotomias até mesmo apropriadas pelas próprias teorias do jornalismo e seus estudos, que, muitas vezes, não dão conta de problematizar de forma comprometida seus discursos autorreferenciais.

Podemos citar o caso, para ficarmos com apenas um exemplo, da retórica produzida pelas agências de checagem, conhecidas como fact checking. Geralmente vendidas como uma ferramenta fundamental no combate às notícias falsas, seu discurso se baseia num ideal de verdade claramente dicotômico: ou temos "fato", ou temos "fake", bastando ao jornalismo separar de forma comprometida o verdadeiro do falso para que suas notícias ganhem um reconhecido estatuto de veracidade. Nesse sentido, estudos como os de Spinelli e Santos $(2018$, p. 20) sustentam que o jornalismo profissional deve assumir "o papel de guardião da credibilidade das notícias", uma vez que, na chamada era da pós-verdade, "em que fatos objetivos são menos relevantes que emoções e crenças pessoais, o jornalismo precisa apostar na sua essência: o compromisso com a qualidade e apuração dos fatos".

É inegável que, eticamente, o jornalismo não deve se desvincular desse compromisso de busca da verdade, quase que pressuposto de sua prática. A questão é que, entre o "fato" e o "fake" a verdade pode tanto quanto a mentira - se esconder e/ou se proliferar das mais diversas maneiras, de acordo com a forma e as conjunturas em que nos é apresentada. (ARENDT, 2009) Não estamos, com isso, querendo relativizar o estatuto da verdade que é imanente a todo e qualquer discurso que trata da realidade e seus fatos. 
A verdade de fato existe e seu horizonte não deve, obviamente, ser negligenciado. Mas a verdade do fato, por si só, não soluciona essa equação tão problemática e complexa. Pelo contrário, pode ajudar a obscurecê-la e/ou ser utilizada deliberadamente como estratégia corporativista de uma instituição que se pretende fazer reconhecida como mais "confiável" e "verdadeira" do que as outras. Uma estratégia que, deliberadamente, acaba por silenciar os traços constitutivos de toda lógica de produção de sentido.

Se levarmos em conta cenários que demandam uma maior interpretação da ordem experiencial do acontecimento, como é o caso dos "cenários complexos inaugurais" - noção proposta por Bruck e Santos (2014) para pensar eventos que geralmente impactam o ordem cotidiana por demandar uma maior compreensão/explicação de seus desdobramentos na sociedade, como, por exemplo, as catástrofes naturais e os novos surtos na saúde pública - podemos perceber que o jornalismo muitas vezes enfrenta uma série de desafios particulares que tendem a se desenvolver sob bases instáveis, lacunas que se abrem em função de "incertezas, generalizações e mitificações", impossibilitando-o de compreender a potencialidade de tais fenômenos, ainda circunscritos em um processo de vir a ser.

No estudo particular dos autores, que analisaram como a imprensa noticiou o fenômeno do crack na capital mineira, foi possível diagnosticar que os jornais em questão apresentaram "nítida instabilidade" em suas coberturas sobre o aparecimento da droga naquele momento, o que acabou por reforçar mitos e tabus sobre o acontecimento. Além disso, a pesquisa nos pareceu importante por evidenciar como o jornalismo, nesses casos, parece não dar conta de perceber as nuances de um cenário que se faz muito mais complexo, limitando-se a enquadrar sua cobertura na simples superfície da experiência ocorrida (BRUCK; SANTOS, 2014). Nesses casos, e na impossibilidade de delinear de forma clara a "verdade" de tais fenômenos, é o próprio jornalismo que pode contribuir para ampliar um clima de incerteza e contradição, uma vez que tais acontecimentos demandam uma complexidade narrativa que vai além da simples descrição factual daquilo que "aconteceu" no mundo (LOPES et al., 2012).

Não podemos induzir, obviamente, que tais limitações sejam resultado apenas do trabalho jornalístico, já que as próprias fontes consultadas pelos jornais, como especialistas e autoridades da área, por exemplo, podem auxiliar a produzir discursos enviesados, com versões contraditórias, divergentes e "incertas" sobre um mesmo acontecimento. No entanto, é justamente nessas brechas que se abrem na e pela complexidade do discurso que o jornalismo deveria explorar suas potencialidades narrativas. A lógica da incerteza, da ruptura e da instabilidade, conforme vimos, é inerente a toda e qualquer produção discursiva, sendo o ato de narrar uma intriga que se constitui por um campo aberto ao universo dos possiveis do acontecimento.

Contudo, para além de uma simples prática discursiva, é preciso também aceitar a "complexidade" como uma forma de se apreender a realidade, circunscrita pela aparente desordem e imprecisão de seus fenômenos. É ela que, de acordo com Morin (2005), nos auxilia a enfrentar a lógica da incerteza e o caráter "poliscópico" da informação; um ponto de partida capaz de dar conta das indeterminações inerentes à ordem do acaso e dos limites de nosso entendimento do mundo. Assim conseguiríamos extinguir "falsas clarezas" oriundas da sua aparente transparência, pensando a complexidade da/na informação como uma trama em constate reconfiguração: "a complexidade nunca se libertará totalmente da incerteza, nunca acederá ao universo das ideias claras e distintas" (MORIN, 2002, p. 329).

Apropriado ao campo do jornalismo, o pensamento complexo nos parece uma importante chave de leitura para problematizar a inerente lógica da "incerteza" que perpassa sua confecção narrativa. Abrir, portanto, o jornalismo a um horizonte menos redutor e determinista, num esforço que possa dar conta de compreender o mundo, mais do que o explicar, mesmo que nas suas inevitáveis limitações e fragilidades 
(KLAUTAU, 2018)'. Um compreender que, nessa perspectiva, não estaria imune às contradições, ao antagônico, às brechas e incompletudes, visto que, pelo contrário, é justamente a partir dessa multiplicidade de sentidos que os acontecimentos nos possibilitam a apreensão de uma realidade dialógica, aberta aos vínculos e à produção do contraditório que se faz em discurso (KÜNSCH, 2005, 2014).

A ideia da "incerteza" perpassa, portanto, a produção do acontecimento, remontado às indeterminações do acaso e tido sempre como algo "improvável", como imprevisto e até mesmo inesperado (MORIN, 2005). Conforme já nos alertou Queré (2005), as rupturas próprias à estrutura do acontecimento nos auxiliam também a problematizar o seu caráter "problemático", encarado a partir das tensões e contradições que the constituem, ou até mesmo pela discordância entre seus elementos

[...] que impedem que se chegue a uma solução mediante a adopção de condutas apropriadas. Está-lhe subjacente um problema a resolver. Problema que, uma vez circunscrito, vai originar um inquérito com vista a defini-lo, analisá-lo (QUERÉ, 2005, p. 20).

A instabilidade e a incerteza são constitutivas, por mais paradoxal que seja, à "verdade" dos acontecimentos jornalísticos. Fundamental, inclusive, para superarmos cânones discursivos da instituição, baseados na suposta exatidão factual das informações, no caráter "objetivo" de seus relatos e na suposta "imparcialidade" no trato com a realidade do mundo. Imaginar o jornalismo co mo uma "máquina distribuidora de incertezas e ambiguidades" é muito difícil, conforme atestou Christofoletti (2008), principalmente para quem está diretamente envolvido e preocupado com a manutenção desses valores. No entanto, se o jornalismo pretende ainda ser reconhecido como um importante mediador da realidade social, valores como a "objetividade" e a "verdade" precisam ser reavaliados. É fundamental repensar, por exemplo, como podemos tensionar a ideia de que o jornalismo produz apenas "relatos precisos" e/ou simplesmente reporta "fatos com objetividade". "Será preciso duvidar mais e mais, pois este é o motor da busca do conhecimento. Entretanto, com uma tolerância maior no convívio com a incerteza" (CHRISTOFOLETTI, 2008, p. 219).

Não é pela mera defesa de uma verdade factual que o jornalismo pode abrir espaços para sair de sua eminente crise. Talvez, seja assumindo que a constituição da verdade de seus discursos é o paradoxo constituinte de sua própria identidade. Uma verdade com pretensões totalizantes, mais do que elucidar nosso o mundo, apaga os traços imanentes de toda sua busca, que está passível às mais diversas relações de poder e disputas pela produção de sentido. Há, portanto, um "fundo de violência" nessa pretensão de verdade que precisamos abandonar (VATTIMO, 2016).

Isso se quisermos, como afirma Vattimo (2016), pensá-la em suas possiveis aberturas, nunca desinteressadas, de partilha social. O "adeus à verdade" seria assim o início, "a própria base, da democracia", no sentido de que nos abriria uma via para desnaturalizar as pretensões tão caras ao discurso midiático de "fornecer a 'verdade' verdadeira" dos acontecimentos, podendo com isso nos concentrar sobre aquilo que está por trás de toda a sua pretensão de objetividade. "Retira também toda possivel legitimidade a todas aquelas políticas que pensam poder aceitar limites à liberdade ou aos interesses de todos com base em uma consideração do que é 'necessário' objetivamente a uma sociedade" (VATTIMO, 2016, p. 16-17).

Perceber a verdade como uma atividade que se constrói a partir de paradigmas coletivamente partilhados e explicitamente reconhecidos pode nos ser de grande utilidade para encarar o jornalismo em seus devidos termos: como uma prática de comunicação que se inscreve a partir de "estratégias sensíveis", que constroem seus discursos sob uma dimensão baseada na aproximação das diferenças e na afetação dos

1 Aqui é importante pontuar o diálogo que a autora faz com a noção de “compreensão" proposta por Arendt, (2008, p. 330): “A compreensão, diferentemente da informação correta e do conhecimento científico, é um processo complexo que nunca gera resultados inequívocos. É uma atividade interminável por meio da qual, em constante mudança e variação, chegamos a um acordo e a uma conciliação com a realidade, tentamos sentir o mundo como nossa casa". 
sujeitos vinculados nessa relação (RANCIÈRE, 2009; SODRÉ, 2006). Trata-se, portanto, de pensar o jornalismo a partir de uma abordagem compreensiva na e pela comunicação, em que a dimensão dos afetos em sua base ética e estética problematiza os fatos em sua (re)valorização cognitiva e simbólica. Compreender esse "comum" é entender os vínculos sob os quais o jornalismo e seus discursos estão arraigados. É inserir o jornalismo, de fato, na experiência cotidiana do mundo (SODRÉ, 2006).

A obsessão pela verdade factual própria aos discursos de autolegitimação do jornalismo parece esconder o fato de que ele, mais do que ninguém, está inserido nessa experiência fundamental da linguagem: um jogo que se dá pela racionalidade do diálogo, mas também pela mobilização de afetos, estéticas políticas baseadas na constituição de um campo extremamente persuasivo e conflituoso (SAFATLE, 2017).

É sob este palco nada estável que os processos de identificação do jornalismo estão alocados e é a partir dele que devemos direcionar nossos olhares, se quisermos problematizá-lo de forma comprometida, em toda sua imanência. Seus embates por legitimação discursiva não se dão necessariamente pela "verdade" de uma proposição, mas pelos "julgamentos valorativos" sob os quais depositamos expectativas quando agimos a partir de determinados critérios. Nesses tempos incertos, onde a verdade parece atuar como estratégia e álibi para legitimar a autoridade da instituição, o que nos falta é "encontrar a palavra nessa sua força instaurada. [...] Compreender circuitos de afetos não é calar a razão, mas ampliá-la" (SAFATLE, 2017, p. 133-136).

\section{Construindo espaços fluidos: narrativas de incertezas para repensar abordagens ao jornalismo}

Nosso percurso metodológico passa pelas considerações de Ginzburg (1989), em seu paradigma indiciário, e de Motta (2013), ao propor sua sistematização de análise crítica da narrativa. Cada um desses autores nos traz, em seu espaço de discussão, elementos para pensar as narrativas jornalísticas que colhemos e destacamos na seção subsequente.

Cabe, nesse contexto, algumas considerações. A primeira diz respeito à observação residual que o historiador italiano Carlo Ginzburg incentiva: "Se a realidade é opaca, existem zonas privilegiadas - sinais, indícios - que permitem decifrá-la" (GINZBURG, 1989, p. 177). Tal proposição nos permite refletir a respeito do que é considerado detalhe ou mesmo sem importância nas análises de jornalismo. É em busca desses indícios, desses rastros narrativos que nem sempre estão em destaque ou explícitos que traçamos nossa observação. Pretendemos, em primeiro lugar, apontar para a possibilidade de construções de espaços fluidos no jornalismo, ou seja, a perspectiva que o jornalismo nos oferece de imaginar cenários que se baseiam em incertezas, em frágeis ideias de mundos, que podem a qualquer momento se dissolver.

A contradição que se apresenta a partir dessas construções - vindo de um jornalismo cujas narrativas estão envolvidas em uma cultura profissional que gira em torno do ideal de objetividade - faz parte do nosso contexto de observação, mas não se torna, ela mesma, um objeto de análise. Aqui, a contradição faz parte dessa construção fluida e instável de cenários. A insegurança que as narrativas jornalísticas parecem dar a ver em determinadas situações, quando permitem reconhecer que a realidade narrada é opaca - e, mesmo ao decifrá-la, as dúvidas são mais frequentes do que as certezas - é a base dessas construções. E para o quê elas apontam, em termos de análise do jornalismo?

Relembremos as palavras da historiadora Lilia Schwarcz, ao prefaciar a obra Comunidades imaginadas, de Benedict Anderson (2008, p. 16): “Nações são imaginadas, mas não é fácil imaginar. Não se imagina no vazio e com base em nada". Falemos, então, sobre os convites a imaginar que são feitos pelo jornalismo - e como podemos abordá-los em análises. Especificamente, partiremos de notícias publicizadas por diferentes veículos de comunicação - uma coleta preliminar, que buscou mapear as principais notícias a respeito do vazamento de óleo que dominou as praias do Nordeste brasileiro, a partir de agosto de 2019. 
A falta de informações mais aprofundadas sobre esse vazamento acaba sendo tanto circunstancial quanto proposital, pois reforça parte da discussão que intencionamos travar: em um ambiente marcado pela instabilidade informacional, por uma verdade fluida, o jornalismo é exposto a tudo aquilo que vem tentando evitar ao longo desses anos. Seu lugar legítimo de fala, construído com base na pretensão de verdade, é colocado em xeque quando "fontes oficiais" divergem, quando não há como obter mais do que aquilo que os meros mortais são acostumados a saber: não há certezas.

Para ilustrar essa discussão e apontar de maneira preliminar algumas possibilidades de observação para essas narrativas, destacamos sete lides - a grande ode à pretensão da objetividade jornalística - a respeito desse vazamento de óleo. Sete construções jornalísticas sobre o caso, colhidas ao longo de um ano e oriundas de diferentes veículos. Sete tentativas de resumir as incertezas e, ao fazer isso, construir espaços fluidos - em que não se sabe se ações são acidentais ou propositais, em que fontes oficiais falam, mas suas informações não acrescentam nada de novo ao panorama já desfragmentado, em que as paisagens estão sujas de óleo, contudo, não se sabe se essa é a pior parte ou quais as suas completas consequências.

Como dito, recolhemos matérias sobre o vazamento de óleo nas praias do Nordeste ao longo de um ano, desde o seu aparecimento, até o seu proclamado fim, mesmo sem oferecer informações suficientes para um desfecho. Dessa coleta inicial, selecionamos sete matérias. Os lides das matérias, que estarão dispostos mais adiante, foram organizados de acordo com a indicação de Motta (2013), quando o autor sugere que o analista de narrativas deve determinar o início, desenvolvimento e fim do enredo que está observando. A análise das conexões que se revelam nas narrativas desses lides, então, foi feita levando em consideração essas demarcações. Para isso, classificamos cada uma das matérias - e, consequentemente, seus lides - em um desses espectros.

Como didaticamente aponta Braga (2008), a base do paradigma indiciário não é colher e descrever indícios, mas selecionar e organizar para fazer inferências - e é nesse sentido que o paradigma e a análise crítica da narrativa figuram no presente trabalho. Com isso, advogamos em prol de um caminho entre caminhos, de uma sistematização que leve em consideração o sensivel.

Também por isso não consideramos aumentar a quantidade de matérias. Aqui, buscamos pela sintaxe da estória que se apresentou sobre o óleo nas praias do Nordeste - o enredo que nos foi revelado por indícios e cujos elementos podem proporcionar questões interessantes para pensar sobre a prática jornalística atual e suas possibilidades de pesquisa. Sete matérias foram suficientes para estabelecer o início, o desenvolvimento e o fim desse enredo.

Voltamo-nos para a potência da incerteza nas narrativas jornalísticas, tentando retirar, a partir olhar jornalístico sobre esses cenários complexos, caminhos de análise. Quando Bruck e Santos (2014) nos mostram que, ao enquadrar superficialmente sua cobertura de "cenários complexos inaugurais", o jornalismo se coloca diante de desafios para ultrapassar as próprias limitações que criou, podemos também pensar em potencialidades. As lacunas de incertezas geram, sim, limitações para a compreensão de fenômenos que se apresentam como rupturas na ordem, inconsistências, inacabados. Mas eles também revelam construções - e leituras - possiveis de uma realidade.

Feitas essas considerações iniciais, passamos às explicitações dos lides selecionados e da maneira como organizamos a observação deles. Como mencionado, buscamos construir um enredo com começo, desenvolvimento e fim para a trama do derramamento de óleo nas praias nordestinas. Para tal, procuramos por notícias que tratassem do caso e do avanço de suas contradições, destacando a falta de respostas consideradas claras.

Adaptando a sugestão de Motta (2013), de identificar um início, um desenvolvimento e um fim, as notícias aqui foram coletadas e organizadas de modo a contar uma estória: 1) passando pelo início, em que um problema surge e é apresentado; 2) desenvolvendo as possiveis causas (e efeitos) para a identificação do problema; 3) proporcionando uma espécie de fechamento, de finalização - ainda que apresente tantas incertezas quanto em seu início. 
A intenção, vale salientar, não é trazer uma análise a respeito de como a imprensa tratou esse vazamento de óleo, se houve ou não imprecisões, se estava ou não confusa. Afinal, já partimos dessas premissas, mas com o objetivo de mostrar que há potencialidades - de análises, principalmente - no descortinamento das idealizações das narrativas jornalísticas. Essas idealizações não estão apenas no ethos profissional, na construção de um lugar legítimo e nas tentativas de fortalecimentos desse lugar por parte dos profissionais e dos discursos jornalísticos. Elas estão também na maneira como abordamos o jornalismo, como o observamos e como tentamos tirar dele objetos de pesquisa.

Não se trata, portanto, de apontar o dedo para potenciais "falhas", mas de reconhecer que essas narrativas fluidas abrem caminhos para repensar a relação do jornalismo com todos os seus elementos fundadores modernos, antevendo que este não é um fim, mas um frutífero, e necessário, recomeço.

Isso posto, esboçamos a nossa narrativa a respeito do óleo nas praias do Nordeste brasileiro: desde o seu aparecimento até as divagações sobre suas consequências, chegando a sua pretensão de finalização. Tomamos a liberdade de usar o termo "divagações" para reforçar justamente o caráter vago que essas narrativas inspiram. E, ao divagar, o jornalismo constrói espaços fluidos, incertos e imprecisos. Mas esses espaços incertos, veremos, ainda narram.

Esse percurso começa com a notícia de um vazamento de óleo em Recife-PE. “Um vazamento de óleo na refinaria Abreu e Lima, no complexo portuário de Suape, no Grande Recife, atingiu parte do manguezal da região na manhã desta terça-feira (27)", diz o lide de 27 de agosto, da Folha de S. Paulo (VALADARES, 2019). Não se sabe a extensão da área atingida, mas cogita-se que a Petrobrás, responsável pelo refinamento de óleo da região, fosse a instituição que poderia ser cobrada.

Quase um mês depois, no entanto, a própria Petrobrás² se exime de qualquer responsabilidade. Em resumo, a companhia emite uma nota, que se inicia:

Analisamos amostras de óleo encontradas ao longo das últimas duas semanas em praias nos estados de Alagoas, Ceará, Paraíba, Pernambuco e Rio Grande do Norte $e$ verificamos que o material encontrado não é produzido e nem comercializado pela companhia (PETROBRÁs, 2019, grifo nosso).

Esse é o nosso início: um esboço de uma problematização, ainda sem elementos suficientes para ser constituída. Há, no entanto, uma intenção do jornalismo de acionar sua expressão de utilidade, de prestação de serviço e cobrança de autoridades. Apesar de não saber exatamente a respeito do que está tratando, busca-se impor sua função social, destacar seu papel na sociedade, em que cobra respostas mesmo que as próprias perguntas se apresentem de maneira difusa.

"Quem é responsável pelo vazamento?", pergunta o jornalismo. E essa questão se tornou a primeira via de discussão desse assunto. E, assim, buscou por um fio de concretude em um mar de incertezas. Não se sabe exatamente o quê ou o porquê: qual o crime cometido - ou mesmo, se há um crime ou um acidente. Não se sabe como e quando: a partir de que lugares o óleo vazou ou dados para confirmar quando o problema começou (apenas marca-se o dia em que foi visto primeiro na costa). Contudo, parte-se em busca do quem. Dizemos isso porque, ao propor que a principal preocupação deveria ser procurar culpados, o jornalismo coloca em suspenso a sua capacidade de prover respostas.

A orientação do olhar, nesses indícios, é de que, diante de não saber explicar, é preciso achar uma voz que saiba. Ao não conseguir estruturar seu enredo a respeito do vazamento com a estrutura elementar de início, desenvolvimento e fim, o jornalismo expõe que a sua narração, em si, não basta; é necessário que outros narradores sejam identificados e se coloquem no meio da imprecisão. E é justamente nessa busca por outros narradores que ultrapassamos o início do nosso enredo. 
Meses depois, já dentro do que imaginamos ser o desenvolvimento da estória, ainda não há quem culpar, mas as manchas continuam aparecendo nas praias do litoral nordestino. 0 fio da trama que se sobressai, agora, é a incerteza em torno da preocupação que o óleo deve causar, pois nem mesmo há consenso em relação a intensidade de sua expansão.

No lide de outra matéria da Folha de S. Paulo, dessa vez do dia 26 de outubro, temos como destaque a possibilidade de o óleo estar diminuindo:

O almirante de esquadra Leonardo Puntel, comandante de operações navais da Marinha, afirmou neste sábado (26) que a presença de petróleo está diminuindo nas praias do Nordeste. Segundo ele, não foram detectadas grandes manchas durante o dia, mas apenas pingos, de retirada mais fácil (FABRINI; CHAIB, 2019, grifo nosso).

No entanto, três dias depois, no dia 29 de outubro, o mesmo jornal reverbera uma fala do ministro da defesa, Fernando Azevedo, em que este pontua que não é possivel saber se a questão está perto de ser resolvida:

O ministro da defesa, Fernando Azevedo, afirmou nesta terça (29), véspera de a poluição com óleo nas praias do Nordeste completar dois meses, ser impossivel prever se o problema está perto do fim. As primeiras manchas de petróleo foram detectadas em 30 de agosto e, segundo ele, não há como mensurar quantidades ou antever rumos que tomarão (FOLHA DE S. PAULO, 2019, grifo nosso).

E as incertezas continuam. Além de não se conseguir precisar se o problema está perto ou não de uma solução, também não há como chegar em um consenso acerca de novas ameaças à costa brasileira. O ruído não se restringe apenas à quantidade de óleo que pode atingir o litoral ou quando - embora tudo isso construa a ideia de espaços fluidos. A imprecisão está também nos posicionamentos das ditas "fontes oficiais", tão caras à construção de ideais no jornalismo moderno.

Seguindo o enredo que traçamos, dessa vez com uma notícia publicada no jornal O Globo, no dia 30 de outubro, é possível perceber como a narrativa confronta posicionamentos diversos de pesquisadores e de instituições como a Marinha e o Ibama:

UFRJ A descoberta foi feita por meio da análise de uma imagem de radar, gerada por um satélite da Agência Espacial Europeia e emitida às 11h da manhã do dia 28 de outubro. Caso haja confirmação, esta teria sido a primeira vez que o óleo teria sido observado na superfície do mar e não nas praias. A Marinha e o lbama, porém, negam sua existência (AZEVEDO; JOHANNS, 2019, grifo nosso).

Por fim, no dia 4 de novembro, no site UOL, o ministro da defesa, a voz oficial do governo para essas circunstâncias, novamente não oferece informações que possam ser validadas pelo discurso jornalístico factual. No entanto, o ministro reaparece na nossa refiguração reforçando as construções incertas de espaço. No lide, temos:

O ministro da defesa, Fernando Azevedo, afirmou hoje que o governo não dispõe da informação sobre a quantidade total de óleo que ainda pode chegar à costa brasileira. 'Nós não sabemos a quantidade derramada, o que está por vir ainda' (AMORIM, 2019, grifo nosso).

Se, como pontua Lage (2001), as fontes oficiais falseiam a realidade e sonegam informações, tanto para manter o poder de grupos dominantes quanto para preservar suas imagens, teríamos uma outra possibilidade para esse entendimento. A exposição da incerteza também por parte das fontes oficiais, atendendo ao que Machado (2002) chama de "supremacia absoluta das fontes oficiais", também pode ser pensada como a contrapartida jornalística. Em termos práticos, ao expor as contradições e a incapacidade 
de fornecer soluções em um contexto de incertezas, as fontes oficiais são também colocadas próximas a um entendimento de incompetência ou mesmo irresponsabilidade.

Não se sabe a origem do óleo, ou a quantidade que foi derramada nas águas. Do mesmo modo, não há informações consistentes sobre as consequências desse desastre para o meio ambiente, nem se há a possibilidade de acontecer novamente. As inconsistências nas narrativas sobre os espaços não estão apenas na dimensão física. Estão nas construções das ideias - de espaços brasileiros, de organização social e política. As fontes oficiais, nesse caso, são parte dessa inconsistência.

E é ainda envolto na inconsistência das fontes oficiais que chegamos à parte final do enredo. 0 "fim" chega com a declaração de que o vazamento ainda é mistério para as autoridades. No lide de uma matéria do Correio Braziliense, já em fevereiro de 2020, é destacado que: "Seis meses depois do aparecimento das primeiras manchas de óleo na Região Nordeste, a Marinha segue sem respostas sobre a possivel origem do material que apareceu no litoral brasileiro em setembro do ano passado" (CARDIM; TEÓFILO, 2020, grifo nosso). A matéria segue explicando as consequências mapeadas, até agora, para o vazamento. Nesse momento, a investigação conduzida pela Polícia Federal e pela Diretoria Geral de Navegação da Marinha ainda estava em andamento.

E, exatamente um ano depois da primeira matéria que destacamos, em 27 de agosto de 2020, no portal G1, é reverberada uma notícia do Jornal Nacional sobre a conclusão da investigação. No lide, explicase: "Um ano depois, a Marinha concluiu a investigação sobre o desastre do derramamento de óleo no litoral nordestino. Mas ainda não encontrou um culpado" (JORNAL NACIONAL, 2020, grifo nosso).

$\mathrm{Na}$ tentativa de destrinchar a conclusão do assunto, a matéria ressalta que a Marinha encerrou as investigações e concluiu que o óleo percorreu 700 quilômetros até chegar na costa do Brasil. E, apesar de ser venezuelano, não necessariamente foi lançado por navios ou empresas do país. "A Marinha esclareceu que, mesmo com o fim da investigação militar, ainda não foi possivel apontar um responsável pelo derramamento", resume e reforça a matéria (JORNAL NACIONAL, 2020, grifo nosso). A busca pelo "quem", foco inicial das narrativas que observamos, é também a maneira como se encerra, por enquanto, o caso.

Assim, podemos ir ao encontro novamente de Queré (2005), quando o autor pensa o acontecimento como algo que está inscrito na experiência, gerando inquietações, rupturas. Sua articulação narrativa não é apenas texto, mas um texto inscrito em um círculo hermenêutico que demanda uma interpretação no e para o mundo. Mais do que um fato que "significa", o acontecimento é aquilo que "se torna", pois tem o poder de tocar a ordem experiencial, inaugurando uma abertura que incita esclarecimentos, que potencializa questionamentos, que nos afeta e faz agir. As coisas mudam quando um novo acontecimento emerge. Ele introduz uma descontinuidade que amplia e até mesmo modifica um mundo de possíveis, tomando rumos e ritmos variáveis (QUERÉ, 2005).

Aludimos novamente também Ricoeur (1995), nessa tentativa de explicitar a mediação narrativa do tempo, da ação humana e, especialmente, do espaço. Aqui, julgamos preparar uma análise com base na tríplice mimese: temos a estrutura pré-narrativa, o mundo da vida; há também configuração desse mundo, por meio dos discursos jornalísticos imbuídos de suas prerrogativas; por fim, tem-se a nossa refiguração. O tempo e o espaço configurados pelo jornalismo - com a sua tentativa de abarcar a fluidez da incerteza em sua pretensão objetiva - encontram a nossa refiguração, apontando tanto para a incongruência dessa performance quanto para as potencialidades de análise que surgem dela.

Retomando a questão trazida no prefácio de Comunidades imaginadas (2008), presente no início desta seção, sobre não ter como imaginar no vazio, o que se pretendeu aqui foi refazer o exercício de configuração jornalística, de se imaginar espaços. A questão é que, nesse caso que apresentamos, a imaginação nos leva a espaços incertos e fragmentários, sendo a sua própria construção cheia de lacunas. E não há necessariamente um problema nisso, reforçamos. 
No entanto, essa dinâmica explicita questões que o jornalismo busca evitar e até negar. Afinal, ao propor a construção de espaços incertos, em sua figuração, o jornalismo também se admite como uma construção incerta - não só em conteúdo, mas em sua forma. Sua forma política, angariada na tentativa de esboçar um mundo preto e branco, sem contornos de cinza; sua forma profissional, em que compromissos com "verdades" e legitimidades quase que autoritárias tentam blindar críticas e seu lugar privilegiado de narrador.

Assumindo essa questão como válida, a refiguração feita por nós e também levada ao incerto, não tem caráter acusatório ou catastrófico. Ela busca ser mais uma proposta de caminho para reflexões do que uma crítica. Se essa performance jornalística é feita até hoje, e encontra terreno fértil nas análises acadêmicas, que buscam atribuir falhas nas paisagens narrativas do jornalismo também como meio de corroborar com um ideal profissional, a culpa também é nossa.

Há outras formas que devem ser buscadas para compreender essas narrativas para além do que elas deveriam ser - e nunca foram, nem nunca serão. A que esperamos ter esboçado leva em consideração justamente a potência do que o jornalismo tem negado para si. A sua "falha" em construir espaços sólidos e objetivos, nos dão espaços fluidos, incertos e inconstantes - e são eles, imperfeitos, contraditórios e multifacetados, que soam muito mais próximos do que apreendemos como "real".

\section{Considerações finais}

Diante da incerteza, o jornalismo se comporta em seu modus operandi tradicional. Essa poderia ser uma das conclusões plausiveis e possiveis para este artigo. Não estaríamos de todo errados. Porém, estaríamos levando em consideração a própria leitura que o jornalismo faz de si e de seu papel na sociedade. Uma leitura idealizada, sabemos, que entrevê uma instituição objetiva, (auto)proclamada mantenedora da democracia, útil e combativa.

Tentamos colocar essas idealizações em suspenso para observar os possíveis caminhos de análise do jornalismo ao lidar com a incerteza. Ao propor essa maneira de olhar, esperamos também ampliar a compreensão em torno do jornalismo brasileiro que se desenvolveu no Brasil, especialmente a partir da década de 1950, rodeado por míticas percepções de si e nas suas pretensões de se constituir a partir dos fatos. E essa não é uma pretensão que pode ser usada impunemente. No século XIX, a noção de fato histórico estava atrelada ao entendimento positivista de que era possivel acessar a verdade dos fatos. Ao historiador, caberia apenas descrevê-los assim como aconteceram, sem que isso pudesse acarretar qualquer tipo de desvio. Um fato histórico seria, nessa perspectiva, um fato político, pois a História Política tradicional exercia um peso grande nessa concepção.

“Primeiro, acerte os fatos; só então corra o risco de mergulhar nas areias movediças da interpretação. Esta é a derradeira sabedoria da escola empírica e do senso comum da História", explica Carr (1996, p.38), como parte de uma crítica a essa visão, como se os historiadores pudessem - e devessem - relatar os acontecimentos partindo sempre da mesma maneira, de forma a não se distinguir quem escreveu o quê (porque o relato em tese seria o mesmo, pensando-se nos termos de uma verdade una dos fatos). Trajetória semelhante parece percorrer o jornalismo de ideal objetivo que floresce no século XIX e se consolida no Brasil do século XX.

Agora, em pleno século XXI, parece-nos oportuno que se busque questionar cada vez mais esses ideais, mas não nos sentidos prévios, de tentar apontar onde o jornalismo não está seguindo a cartilha que criou para si. Mas, sim, aventurando-se nas lacunas que surgem daí. Neste artigo, então, trouxemos uma sugestão: partimos do que seria uma dessas lacunas, a explicitação da incerteza e da imprecisão no jornalismo. Esse é um incômodo ao lugar de fala jornalístico, mas que traz a possibilidade de discutir a capacidade do jornalismo em construir espaços opostos, contraditórios, mas complementares. Essa é uma força que se apoia também em sua autoridade, ancorada justamente nesses ideais que nos parecem tão frágeis. 


\section{Referências}

ALBUQUERQUE, Afonso. A narrativa jornalística para além dos faits-divers. Lumina, Juiz de Fora, v. 3, n. 2, p. 69-91, jul./dez. 2000. Disponivel em: <http://www.ufjf.br/facom/files/2013/03/R5-Afonso-HP.pdf>. Acesso em: 06 jan. 2020.

AMORIM, Felipe. Defesa contradiz Bolsonaro sobre óleo e diz não saber se pior está por vir. UOL, Brasília, 4 de nov. 2019. Disponivel em: <https://noticias.uol.com.br/meio-ambiente/ultimas-noticias/ redacao/2019/11/04/nao-sabemos-quanto-oleo-ainda-pode-chegar-as-praias-diz-ministro-da-defesa. htm>. Acesso em: 12 dez. 2019.

ARENDT, Hannah. Compreender: formação, exílio e totalitarismo. São Paulo: Companhia das Letras, 2008.

Entre o passado e o futuro. São Paulo: Perspectiva, 2009.

AZEVEDO, Ana Lucia; JOHANNS, Eller. Marinha e Ibama negam mancha de óleo de $200 \mathrm{~km}$, mas UFRJ mantém alerta. 0 Globo, Rio de Janeiro, 30 out. 2019. Disponivel em: <https://oglobo.globo.com/ sociedade/oleo/marinha-ibama-negam-mancha-de-oleo-de-200km-mas-ufrj-mantem-alerta-24050026>. Acesso em: 15 dez. 2019.

BARBOSA, Mariana (Org). Pós-verdade e fake news: reflexões sobre a guerra de narrativas. Rio de Janeiro: Cobogó, 2019.

BARTHES, Roland et al. Análise estrutural da narrativa. Petrópolis: Vozes, 1971.

BENNETI, Marcia; HAGEN, Sean. Jornalismo e imagem de si: o discurso institucional das revistas semanais. Estudos em Jornalismo e Mídia, ano VII, n. 1, p. 123-135, jan./jun. 2010.

BERGER, Peter; LUCKMANN, Thomas. A construção social da realidade: tratado de sociologia do conhecimento. 23. ed. Petrópolis: Vozes, 2003.

BIRD, Elizabeth: DARDENNE, Robert. Mito, registro e "estórias": explorando as qualidades narrativas das notícias. In: TRAQUINA, Nelson (Org.). Jornalismo: questões, teorias e "estórias". 2. ed. Lisboa: Vega, 1993.

BONSANTO, André. A verdade dita é dura: "histórias da verdade" do/no jornalismo e a ditadura militar no Brasil. 2018. 387 f. Tese (Doutorado em Comunicação) - Universidade Federal Fluminense, Niterói, 2018.

BRUCK, Mozahir Salomão; SANTOS, Bruno Raquel de Oliveira. O fazer jornalístico e o enfrentamento de cenários complexos inaugurais. Estudos em Jornalismo e Mídia, v. 11, n. 2, p. 569-583, jul/dez. 2014.

CÂMARA, Clara Bezerril. A "mentalidade escândalo": uma análise das narrativas de malfeitos a partir das polarizações suscitadas no jornalismo brasileiro. 2019. 260 f. Tese (Doutorado em Comunicação) Universidade Federal Fluminense, 2019. 
CARDIM, Maria Eduarda; TEÓFILO, Sarah. Vazamento de óleo em praias do Nordeste ainda é mistério para autoridades. Correio Braziliense, Brasília, 20 de fev. 2020. Disponivel em: <https://www.correiobraziliense. com.br/app/noticia/brasil/2020/02/20/interna-brasil,829204/vazamento-de-oleo-em-praias-do-nordesteainda-e-misterio-para-autorida.shtml>. Acesso em: 20 set. 2020.

CARR, Edward Hallet. Que é história? Rio de Janeiro: Paz e Terra, 1996.

CHARAUDEAU, Patrick. Discurso das mídias. São Paulo: Contexto, 2006.

CHRISTOFOLETTI, Rogério. O jornalismo entre a dúvida e a incerteza: reflexões sobre a natureza da atividade. Comunicação \& Sociedade, São Bernardo do Campo, a. 29, n. 50, p. 203-221, 2. sem. 2008.

CORNU, Daniel. Jornalismo e verdade: para uma ética da informação. Lisboa: Instituto Piaget, 1999.

D'ANCONA, M. Pós-verdade: a nova guerra contra os fatos em tempos de fake news. Barueri: Faro Editorial, 2018.

FABRINI, Fábio; CHAIB, Julia. Volume de óleo nas praias do nordeste diminuiu, diz Marinha". Folha de S. Paulo, Brasília, 26 out. 2019. Disponivel em: <https://www1.folha.uol.com.br/ambiente/2019/10/volume-deoleo-nas-praias-do-nordeste-diminuiu-diz-marinha.shtml>. Acesso em: 10 dez. 2019.

FILGUEIRAS, Isabel et al. Jornalismo em tempos de pós-verdade. Fortaleza: Dummar, 2018.

FRANÇA, V. O acontecimento e a mídia. Galáxia, São Paulo, n. 24, p. 10-21, dez. 2012.

FRIAS FILHO, Otavio. O que é falso sobre fake news. Revista USP, São Paulo, n. 116, p. 39-44, jan./mar., 2018.

GINZBURG, Carlo. Mitos, emblemas, sinais. Rio de Janeiro: Companhia das Letras, 1989.

GOMES, Wilson. Jornalismo, fatos e interesses: ensaios de teoria do jornalismo. Série jornalismo a rigor. v. 1. Florianópolis: Insular, 2009.

GREIMAS, Algirdas Julien. Elementos para uma teoria da interpretação da narrativa mítica. In: BARTHES, Roland et al. Análise estrutural da narrativa. Petrópolis: Vozes, 1971.

HABERMAS, Jürgen. Mudança estrutural da esfera pública: investigações sobre uma categoria da sociedade burguesa. São Paulo: Editora Unesp, 2014.

JÁCOME, Phellipy Pereira. Jornalismo e autolegitimação: a historicidade dos discursos autorreferentes. Leituras do jornalismo. ano 1, n. 2, p. 54-66, jul./dez. 2014.

KLAUTAU, Carolina Moura. Jornalismo, Incerteza e Complementaridade de Opostos: Um diálogo compreensivo. 2018. 268f. Dissertação (Mestrado em Comunicação) - Faculdade Cásper Líbero, São Paulo, 2018.

KÜNSCH, Dimas A. Comprehendo ergo sum: Epistemologia complexo-compreensiva e reportagem jornalística. Communicare, v. 5, n. 1, p. 43-54, 1ㅇ sem. 2005. 
A comunicação, a explicação e a compreensão: ensaio de uma epistemologia compreensiva da comunicação. Líbero, v. 17, n. 34, p. 111-122, jul./dez. 2014.

LAGE, Nilson. A reportagem: teoria e técnica de entrevistas e pesquisa jornalística. Rio de Janeiro: Record, 2001.

LOPES, Fernanda Lima. Auto-referência, discurso e autoridade jornalística. BOCC - Biblioteca on-line de Ciências da Comunicação, Labcom, 2007.

LOPES, Felisbela et al. E. coli: uma doença em notícia em discursos de incerteza e contradição.

Observatorio Journal, vol.6 - nô1, p. 159-181, 2012.

MACHADO, Elias. O ciberespaço como fonte para os jornalistas. Biblioteca Online de Ciências da

Comunicação, Universidade da Beira Interior, 2002. Disponível em: <http://www.bocc.ubi.pt/pag/machadoelias-ciberespaco-jornalistas.pdf>. Acesso: 21 set. 2020.

MARINHA conclui investigação sobre derramamento de óleo, mas não encontra culpado. Jornal Nacional, 27 ago. 2020. Disponivel em: <https://g1.globo.com/jornal-nacional/noticia/2020/08/27/marinha-concluiinvestigacao-sobre-derramamento-de-oleo-mas-nao-encontra-culpado.ghtml>. Acesso em: 20 set. 2020.

MOTTA, Luiz Gonzaga. "Teoria da notícia: entre o real e o simbólico". In: MOUILLAUD, Maurice; PORTO, Sérgio Dayrell (Orgs.). 0 jornal: da forma ao sentido. Brasília: Paralelo 15, 1997.

. Jornalismo e configuração narrativa da história do presente. Revista Contracampo, n. 12, p. 23-50, 2005.

Análise crítica da narrativa. Brasília: Editora UnB, 2013.

MORIN, Edgar. O Método: 1. a natureza da natureza. Porto Alegre: Sulina, 2002.

. Introdução ao pensamento complexo. Porto Alegre: Sulina, 2005.

NÃO SE SABE se poluição com óleo em praias está perto do fim, diz ministro da Defesa. Folha de S. Paulo. Brasília, 29 out. 2019. Disponivel em: <https://www1.folha.uol.com.br/ambiente/2019/10/nao-se-sabe-sepoluicao-com-oleo-em-praias-esta-perto-do-fim-diz-ministro-da-defesa.shtml>. Acesso em: 10 dez. 2019.

NERONE, John. The journalism tradition. In: EADIE, William F. (Ed.). 21st Century Communication: A Reference Handbook. Beverly Hills: Sage, 2009.

The historical roots of the normative model of journalism. Journalism, v. 14, n. 4, p. 446-458, 2012.

History, Journalism, and the Problem of Truth. In: BRENNEN, Bonnie (Ed.) Assessing Evidence in a

Postmodern World. Diederich Studies in Communication and Media. n.3. Milwaukee: Marquette University Press, 2013.

PETROBRÁS. Esclarecemos que o óleo encontrado em praias do Nordeste não é da Petrobrás. Petrobrás, 25 set., 019. Disponivel em: <http://www.petrobras.com.br/fatos-e-dados/esclarecemos-que-oleoencontrado-em-praias-do-nordeste-nao-e-da-petrobras.htm>. Acesso em: 12 dez. 2019. 
PROPP, Vladimir. As raizes históricas do conto maravilhoso. São Paulo: Martins Fontes, 2002.

QUÉRÉ, Louis. Entre facto e sentido: a dualidade do acontecimento. Trajectos - Revista de Comunicação, Cultura e Educação, Lisboa, n. 6, p. 59-75, 2005.

RANCIĖRE, Jacques. A partilha do sensivel: estética e política. São Paulo: EXO experimental org; Editora 34, 2009.

RESENDE, Fernando. O olhar às avessas: a lógica do texto jornalístico. In: ENCONTRO ANUAL DA ASSOCIAÇÃO NACIONAL DOS PROGRAMAS DE PÓS-GRADUAÇÃO EM COMUNICAÇÃO, 13., 2004. Anais... São Bernardo do Campo: E-Compós, 2004. Disponivel em: <http://www.compos.org.br/data/biblioteca_668. pdf>. Acesso em: 14 dez. 2019.

. Jornalismo e suas Narrativas: as Brechas do Discurso e as Possibilidades do Encontro. Revista Galáxia, São Paulo, n. 18, p.31-43, dez. 2009.

. Falar para as massas, falar com o outro: valores e desafios do jornalismo. In: FRANÇA, V; VAZ, P. (Orgs.) Comunicação midiática: instituições, valores, cultura. Belo Horizonte: Autêntica, 2012.

RICOEUR, Paul. História e verdade. Rio de Janeiro: Forense Editora, 1968.

Tempo e narrativa (Tomo I). Trad. Marina Appenzeller. Campinas: Papirus, 1995.

SAFATLE, Vladimir. É racional parar de argumentar. In: DUNKER, Christian et al. Ética e pós-verdade. Porto Alegre: Dublinense, 2017.

SCHUDSON, Michael. The politics of narrative form: The emergence of news conventions in print and television. Daedalus, p. 97-112, 1982.

SCHWARCZ, Lilia. Apresentação: Imaginar é difícil (porém necessário). In: ANDERSON, Benedict. Comunidades imaginadas: reflexões sobre a origem e a difusão do nacionalismo. São Paulo: Companhia das Letras, 2008.

SODRÉ, Muniz. As estratégias sensiveis: afeto, mídia e política. Petrópolis: Editora Vozes, 2006.

A narração do fato: notas para uma teoria do acontecimento. Petrópolis: Vozes, 2009.

SPINELLI, Egle Müller; SANTOS, Jéssica de Almeida. Jornalismo na era da pós-verdade: fact-checking como ferramenta de combate às fake news. Revista Observatório, Palmas, v. 4, n. 3, p. 739-782, mai. 2018.

TODOROV, Tzvetan. As estruturas narrativas. São Paulo: Editora Perspectiva, 1969.

TUCHMAN, Gaye. A objectvidade como ritual estratégico: uma análise das noções de objectividade dos jornalistas. In: TRAQUINA, Nelson (Org.). Jornalismo: questões, teorias e "estórias". Lisboa: Vega, 1993. 
VALADARES, João. Vazamento de óleo em refinaria de Pernambuco atinge manguezal. Folha de S. Paulo, Recife, 27 ago. 2019. Disponivel em: <https://www1.folha.uol.com.br/ambiente/2019/08/vazamento-deoleo-em-refinaria-de-pernambuco-atinge-manguezal.shtml>. Acesso em: 14 dez. 2019.

VATTIMO, Gianni. Adeus à verdade. Petrópolis: Vozes, 2016.

WHITE, Hayden. Trópicos do discurso: ensaios sobre a crítica da cultura. São Paulo: Edusp, 1994.

ZELIZER, Barbie. When facts, truth, and reality are God-terms: on journalism's uneasy place in cultural studies. Communication and Critical/Cultural Studies, v. 1, n. 1, p. 100-119, 2004. 


\section{Informações para textos em coautoria}

\section{Concepção e desenho do estudo}

Clara Câmara e André Bonsanto

Aquisição, análise ou interpretação dos dados

Clara Câmara e André Bonsanto

\section{Redação do manuscrito}

Clara Câmara e André Bonsanto

Revisão crítica do conteúdo intelectual

Clara Câmara e André Bonsanto

\section{Informações sobre 0 artigo}

Resultado de projeto de pesquisa, de dissertação, tese

Não se aplica

\section{Fontes de financiamento}

Os autores são bolsistas PNPD/Capes.

\section{Considerações éticas}

Não se aplica.

\section{Declaração de conflito de interesses}

Não se aplica.

\section{Apresentação anterior}

Não se aplica.

Agradecimentos/Contribuições adicionais

Não se aplica. 